\title{
ARTE PÚBLICO EN EL BARRIO EL PRADO (BARRANQUILLA) Ejercicio de estilo
}

\author{
Antoni Remesar \\ Universitat de Barcelona. Centre Recerca POLIS \\ e-mail: aremesar@ub.edu
}

\section{RESUMEN}

Este artículo tiene como finalidad estudiar el arte público del barrio de El Prado en Barranquilla. Para ello se analiza el contexto urbano general de la ciudad incluyendo muestras de arte público de otras zonas urbanas de esta ciudad.

El artículo se estructura como un "ejercicio de estilo" que pone en diálogo el "sentir" y el "saber". Un sentir derivado de la experiencia vivencial sobre el territorio obtenida en tres viajes a esta ciudad, que se complementa con el saber analítico derivado del estudio de las distintas problemáticas planteadas. Es por ello que, desde el punto de vista de la lectura, se ha utilizado una diferenciación en la tipografía y en el color de la misma. La tipografía Calibri light en negro describe las sensaciones de un azotacalles, término castellano próximo al flâneur baudelairdiano pero sin su carga elitista, inmerso en territorio. La tipografía Courier en granate, contrasta la información obtenida sensorialmente con la documentación de análisis utilizada.

PALABRAS CLAVE: Barranquilla; El Prado; Arte Público

\section{SUMMARY}

This article aims to study the public art of the El Prado neighbourhood in Barranquilla. For this, the general urban context of the city is analysed, including samples of public art from other urban areas of this city.

The article is structured as an "exercise in style" that puts into dialogue "feeling" and "knowing". 
A feeling derived from the experience on the territory obtained in three trips to this city, which is complemented by the analytical knowledge derived from the study of the different issues raised. That is why, from the point of view of reading, a differentiation has been made in typography and its colour. The Calibri light font in black describes the sensations of a gadabout, a Spanish term close to the Baudelairdian flâneur but without its elite charge, immersed in territory. The Courier typography in garnet, contrasts the information obtained sensory with the used analysis documentation.

KEY WORDS: Barranquilla; El Prado; Public Art

\section{RESUM}

Aquest article té com a finalitat estudiar l'art públic de barri de El Prado a Barranquilla. Per això s'analitza el context urbà general de la ciutat incloent mostres d'art públic d'altres zones urbanes d'aquesta ciutat.

L'article s'estructura com un «exercici d'estil» que posa en diàleg el «sentir» i el «saber». Un sentir derivat de l'experiència vivencial sobre el territori obtinguda en tres viatges a aquesta ciutat, que es complementa amb el saber analític derivat de l'estudi de les diferents problemàtiques plantejades. És per això que, des del punt de vista de la lectura, s'ha utilitzat una diferenciació en la tipografia i en el seu color. La tipografia Calibri light en negre descriu les sensacions d'un passejant, terme castellà proper al flâneur baudelairdià però sense la seva càrrega elitista, immers en territori. La tipografia Courier en granat, contrasta la informació obtinguda sensorialment amb la documentació d’anàlisi utilitzada.

PARAULES CLAU: Barranquilla; El Prado; Art Públic 

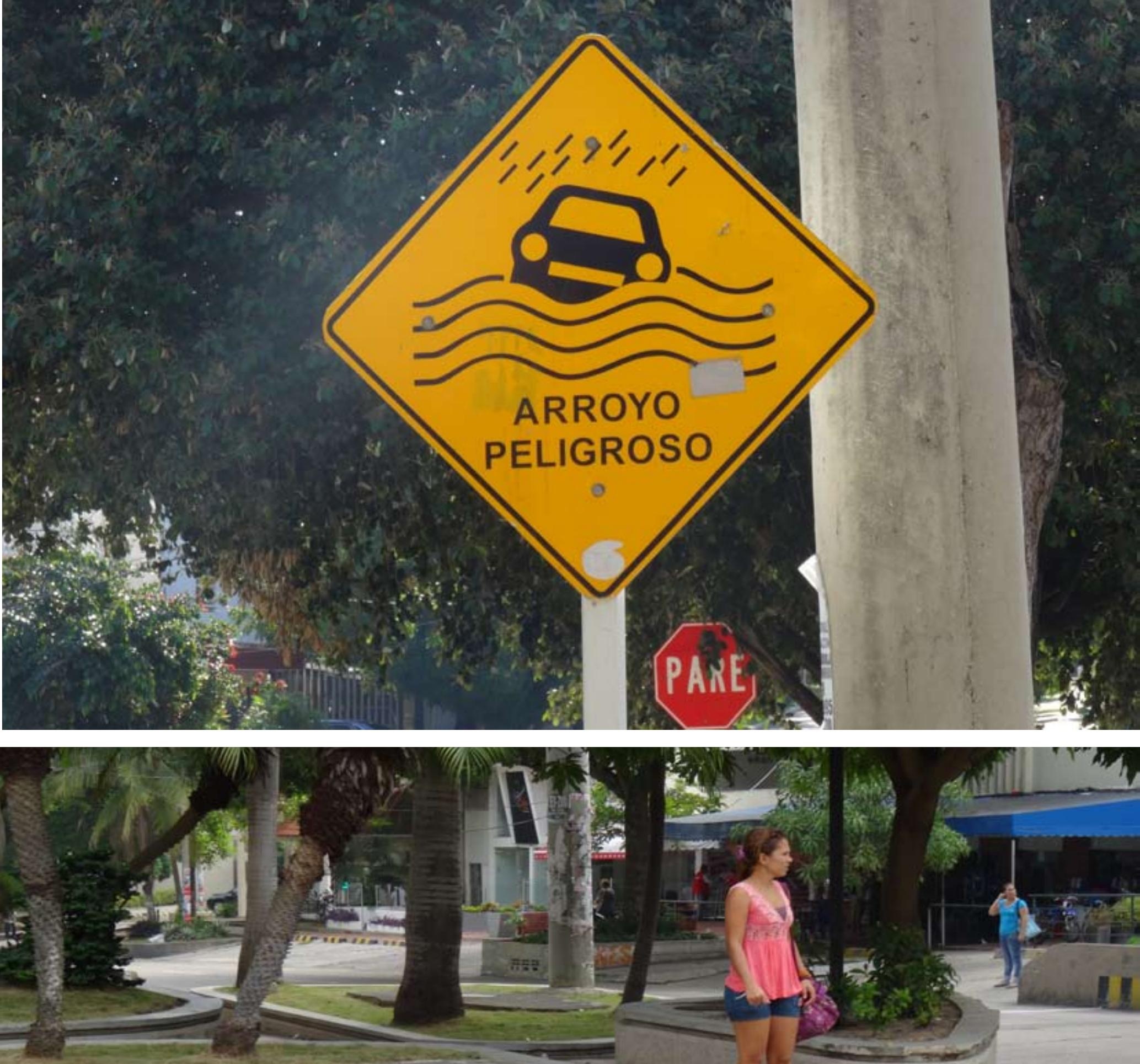
ciudad Condal. En otras palabras, mientras los barceloneses se apiñan con una densidad bruta de 160 h/Ha, los barranquilleros lo hacen más espaciadamente con una densidad bruta de $81,6 \mathrm{~h} / \mathrm{Ha}$. Si se prefiere en densidad por km2, Barcelona concentraría 16.200 h/km2 y Barranquilla, prácticamente la mitad, $8.166 \mathrm{~h} / \mathrm{Km} 2$. Si normalmente Barcelona se define como una ciudad densa, podríamos apuntar que Barranquilla es más una ciudad extensa, especialmente si tomamos en consideración que no existe solución de continuidad entre el municipio de Barranquilla y el de Soledad. Y como ciudad extensa, con unas frágiles redes de transporte ¿público? ¿colectivo? ¿masivo?.

Aún por acabar de articular el sistema integrado de transporte, son precisas otras alternativas para llegar desde el punto donde nos desembarca un elemento de la red a nuestra casa en los barrios más periféricos o ajenos a la capilaridad de los colectivos. El bicing no está implantado y los carriles bici son, todavía, un sueño. La alternativa son las motos. Para un único viajero. En el casco y el chaleco del conductor perfectamente rotulados su célula de identificación y la matrícula del vehículo. Todo por seguridad, por si acaso. Se acuerda el recorrido y el precio.

Como en el caso de Barcelona con las Rondas, prácticamente la totalidad de Barranquilla está ceñida por un cinturón de circunvalación que además marca la frontera con otros términos municipales como el de soledad.

Un cinturón que transcurre al aire libre - a tramos a nivel de rasante a tramos elevado- desde el que se puede contemplar el paisaje o incluso oír algún tiroteo. Como es habitual en este tipo de trazado, de vez en cuando, rotondas y cruces ornados con arte público.

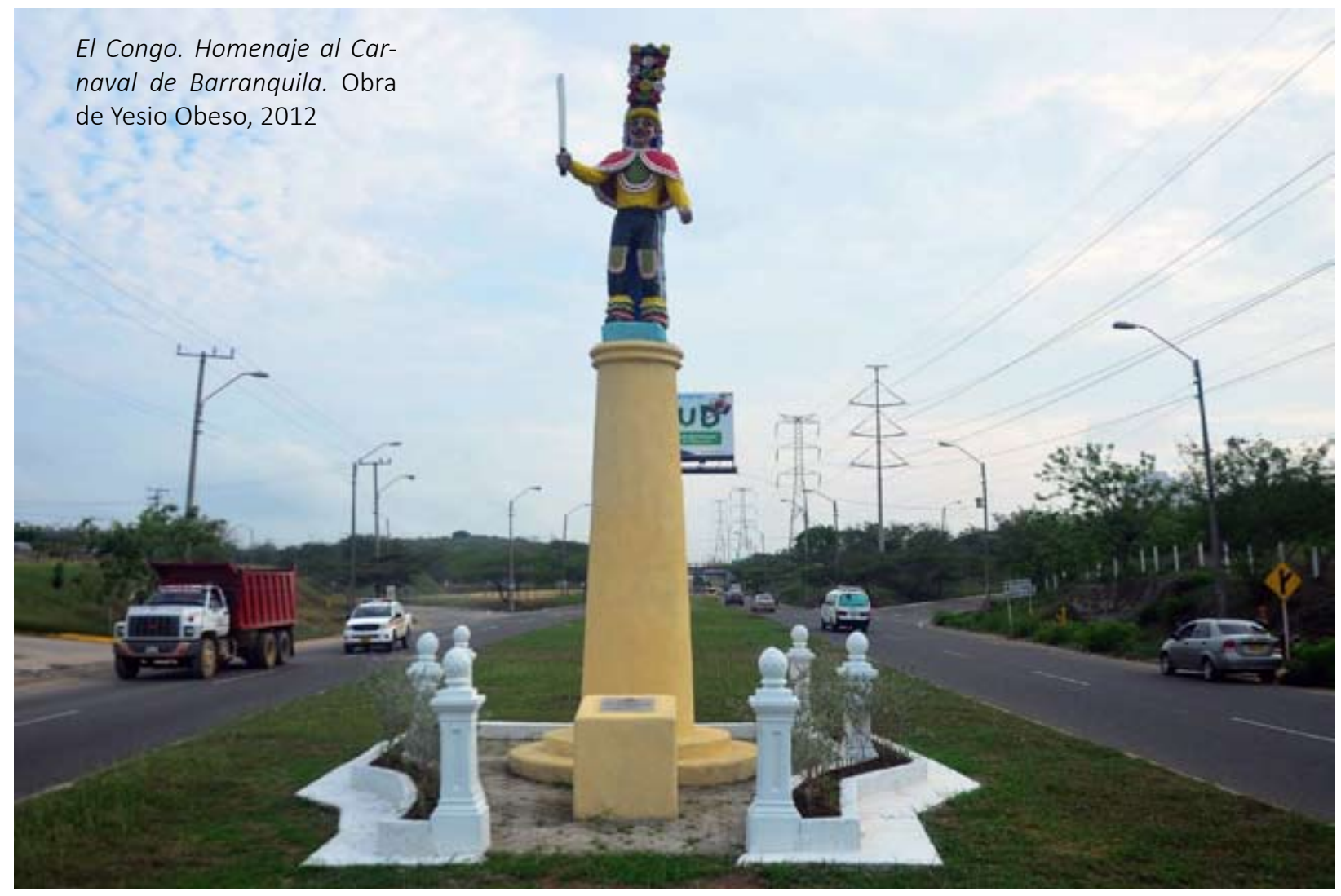




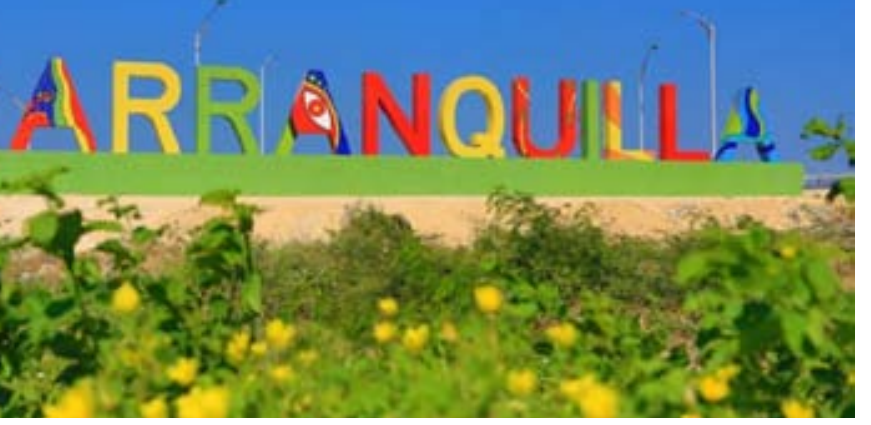

Letras de Barranquilla (hormigón recubierto de cerámica) de Elsa Maria Losada 30 metros de longitud. 2013. Fuente alcaldía de Barranquilla

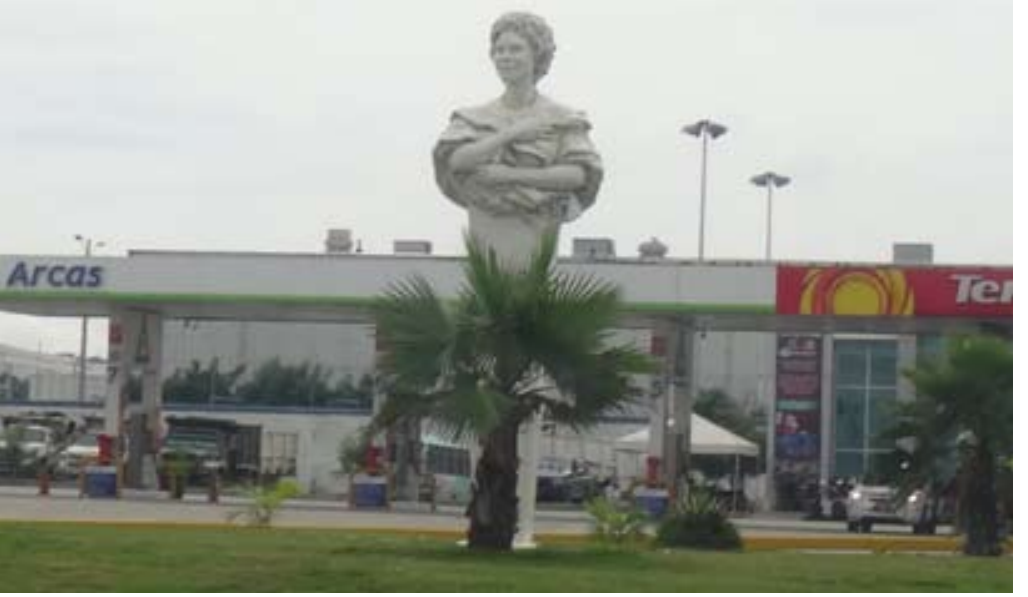

Monumento a Adela de Chars (en marmol?). de Yino Márquez. 2010

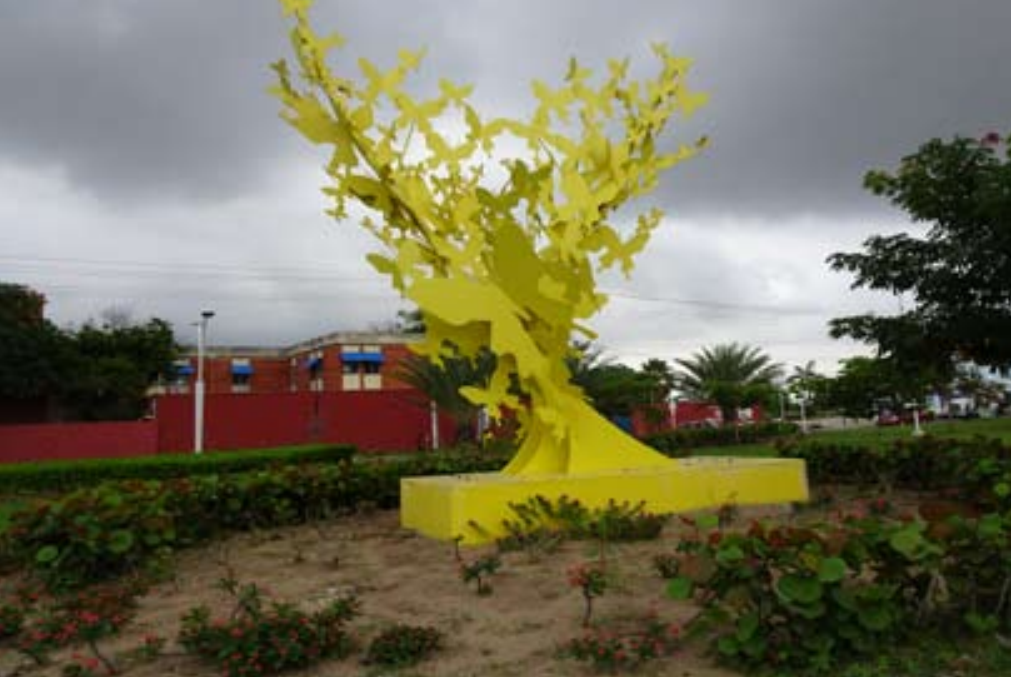

Mariposas amarillas. Homenaje a Gabriel García Márquez (hierro pintado) de Henry Alvear. 2015

Monumento a Shakira (Acero corten) obra de Dietter Patt de $5 \mathrm{~m}$. altura.2006. Fuente: Los monumentos hablan en Barranquilla

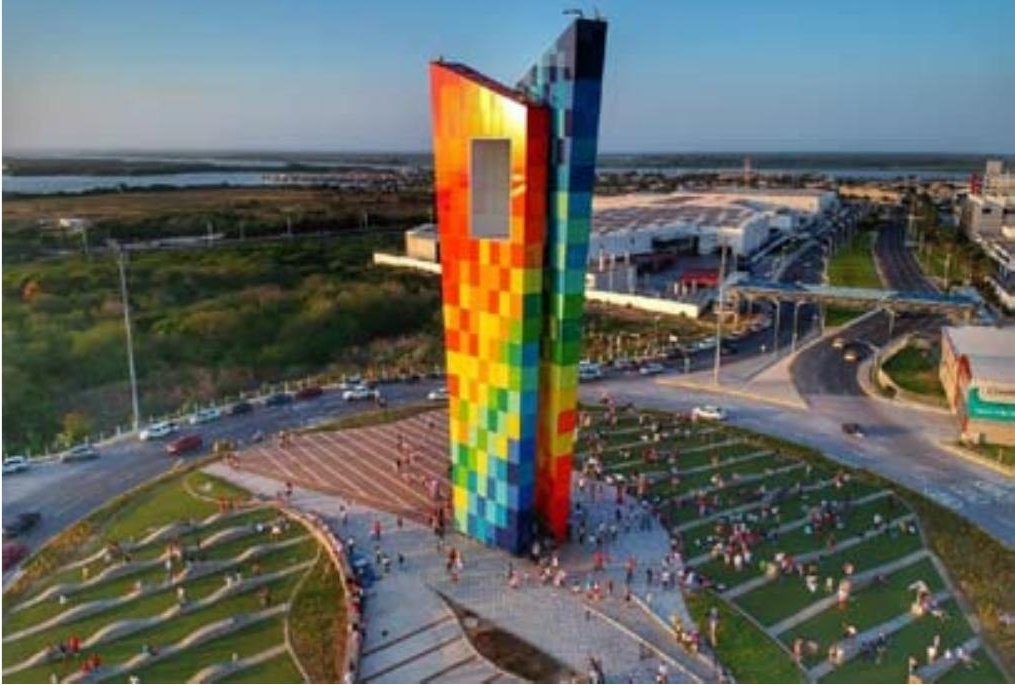

Ventana al mundo (Acero almallena A572-GR.50 y tubería estructural A500-GR.C y vidrio de colores) de Diana Escorcia 47,5 m altura. 2018. Fuente: Smart Steel co.

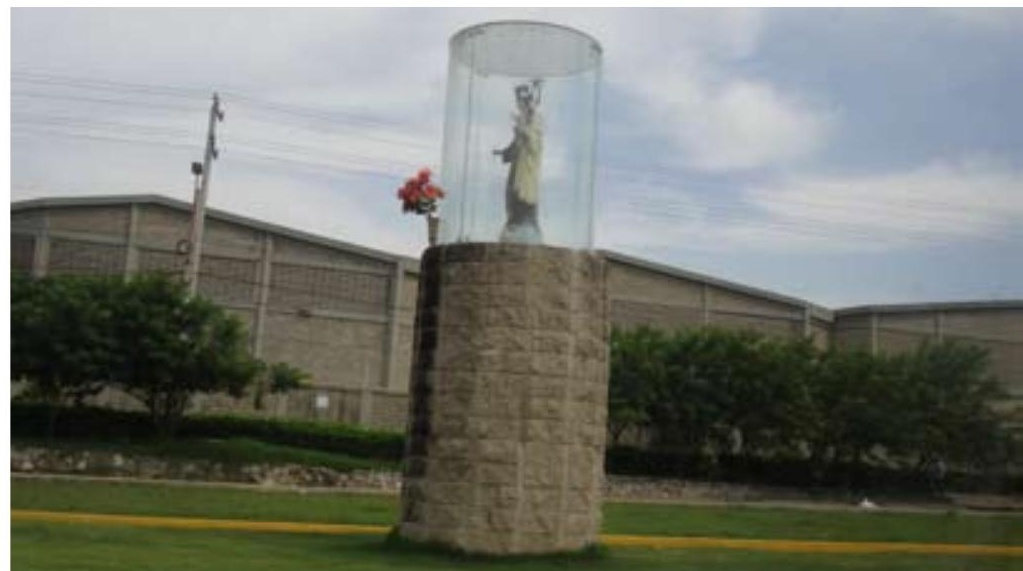

Monumento a la Virgen del Carmen

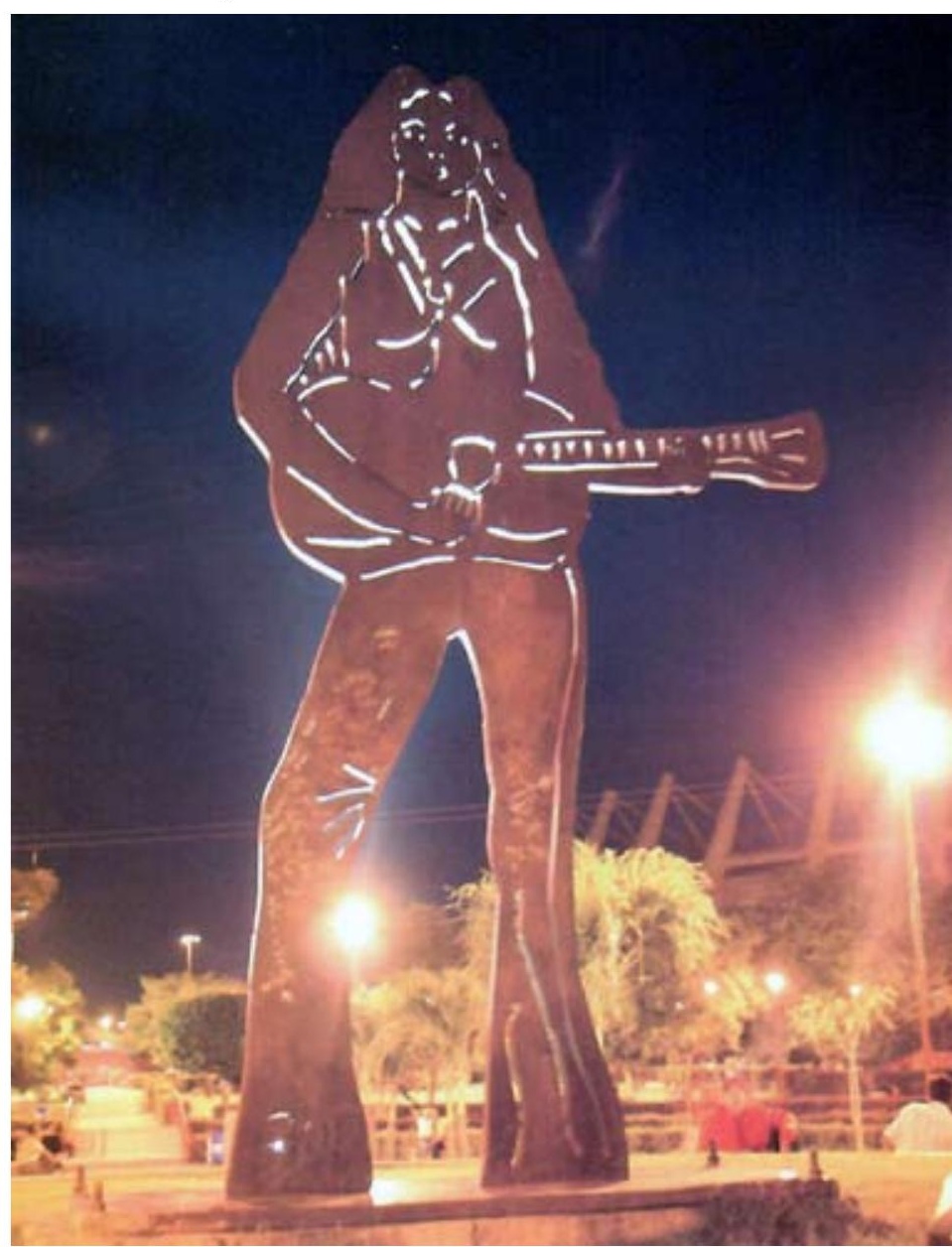




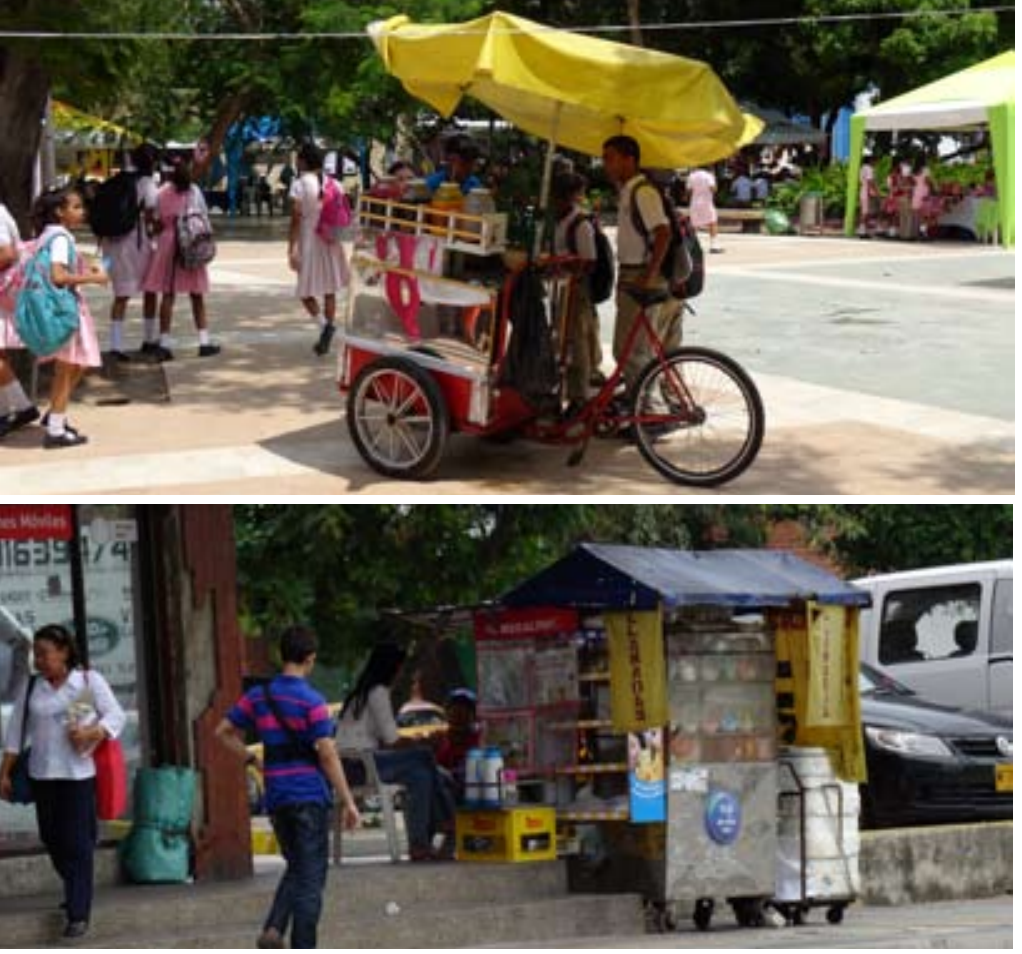

Al hacer camino al andar se percibe la gran cantidad de puestecitos móviles que nos ofrecen café - no lo olemos porqué está encerrado en sus termos, comida -arroz de lisa, arepas de huevo, carimañolas, patacones - ¡Uhmmm! estos puestos Sí que huelen. Los que ofrecen raspados, agua de panela, agua de coco o los fantásticos y coloridos "bolis", así como los que venden frutas no tienen tanto aroma. Por fruta que no quede. En cualquier rincón de la ciudad los sufridos vendedores ambulantes ofrecen al viandante o al conductor el olor y el sabor de las deliciosas frutas tropicales. Algunos de estos puestos ambulantes ofrecen, además, el servicio de llamadas puesto que en Barranquilla las cabinas están desaparecidas o recarga de la tarjeta del teléfono móvil.

En Barranquilla no hay palomas. O si las hay son poco visibles. ¿Podrían ser Tierrelitas? En cambio, abundan las Marías Mulatas (Quiscalus mexicanus) y a primera vista una especie de buitres que no son tal: los jotes cabeza colorada (Cathartes aura) .

La María Mulata tiene su propio monumento obra de Enrique Grau. Una enorme pieza de plancha metálica. Una escultura que también está presente en Cali, Cartagena y Valledupar

Impasibles ante los accidentes que pueden causar las iguanas verdes (Iguana iguana) se atreven a cruzar la vía 40 y se enseñorean de muchos de los espacios verdes de la ciudad. La iguanas comparten su hábitat-los frondosos árboles- con las ardillas de cola roja (Sciurus granatensis) . 



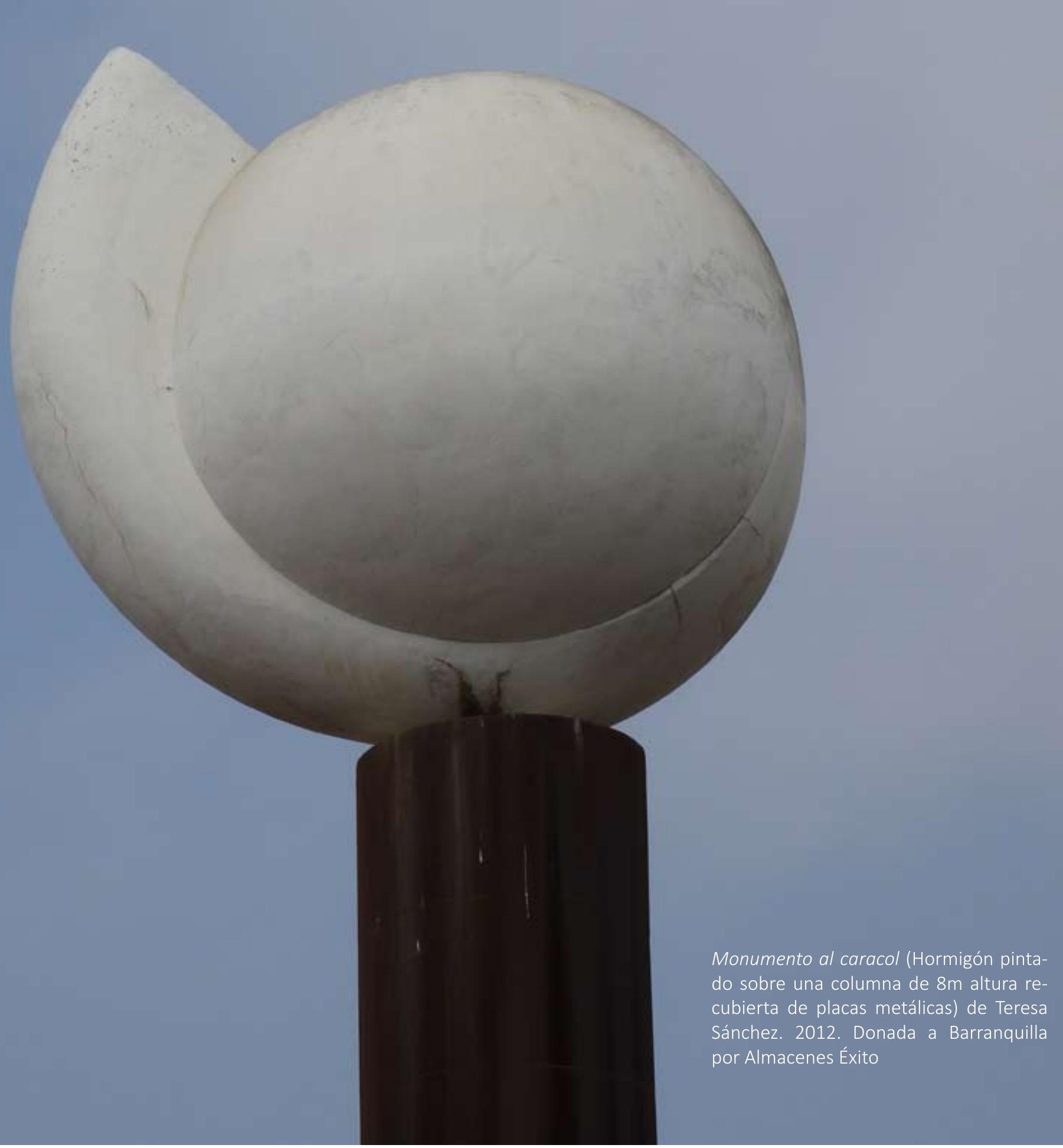

predeterminado, generalmente fibra de vidrio aunque en Barranquilla las cayenas eran metálicas, se genera una forma que es intervenida por distintos artistas- y a la que seguirían, en una escala global, los "Peanuts on Parade",, los "Buddy Beär", o las más locales, "Dogny", el "Tree Parade10", "Hearts a Bluhm 11" o la extraña muestra "El qui porta la lluna" en el aeropuerto de Barcelona en 2009.

7.- El primer tributo a Charles Schulz, Peanuts On Parade, se realizó durante el verano de 2000, poco después de la muerte de Schulz.

8.- Creados por Eva y Klaus Herlitz en el año 2001, en cooperación con el escultor austriaco Roman Strobl

9.- America's Tribute to Search and Rescue Dogs tras los atentados del 11 de septiembre de 2001 en New York

10.- Un proyecto educativo de la Dirección General de Recursos Forestales de Portugal celebrado en 2007

11.- Chicago 2011. "Hearts a Bluhm" es la primera campaña de educación y sensibilización del consumidor lanzada por el Instituto Cardiovascular Bluhm para generar una conciencia generalizada sobre la prevención y el tratamiento de las enfermedades cardiovasculares. 
"Parade" de las cayenas

Barranqulla 2013

\section{.}

basusest

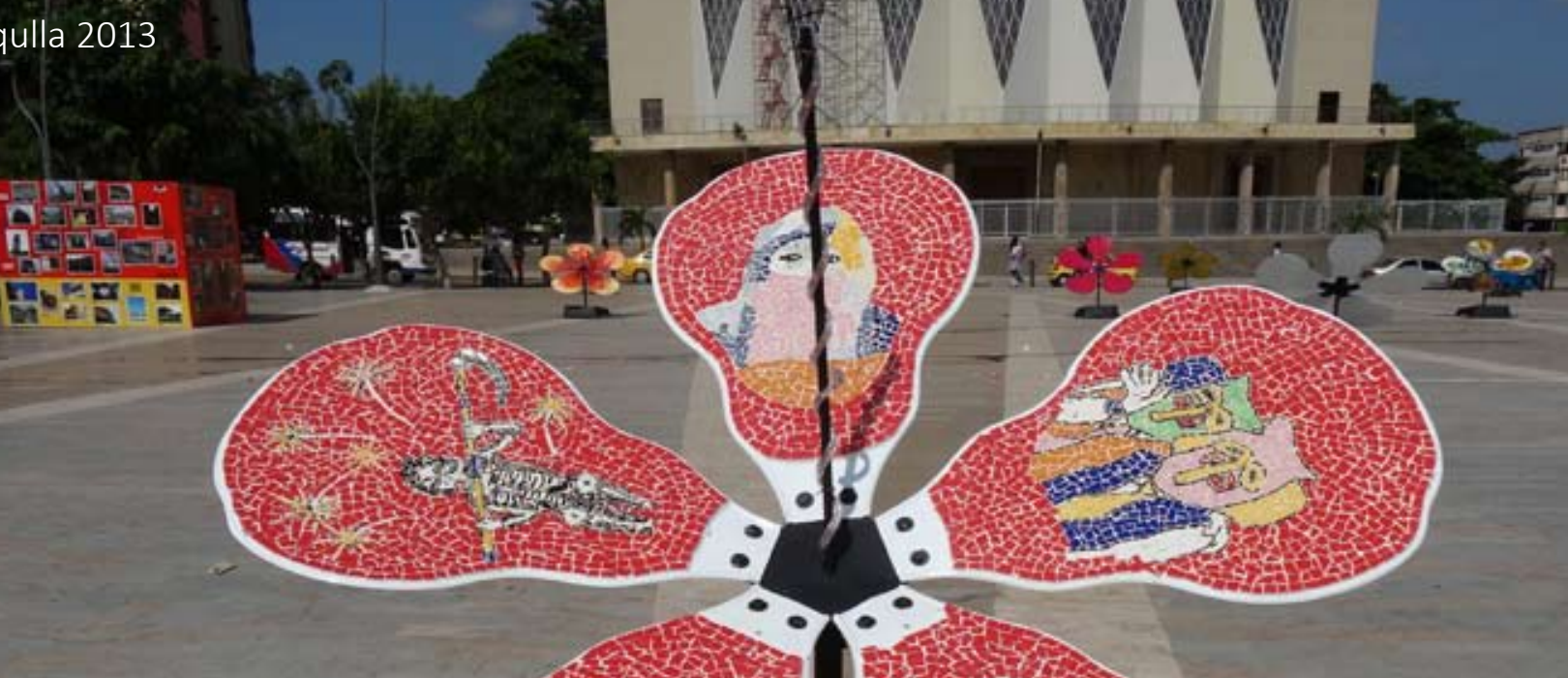

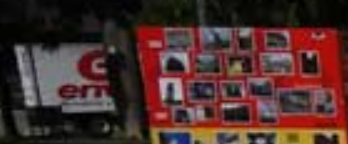

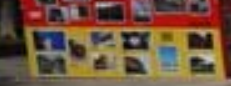
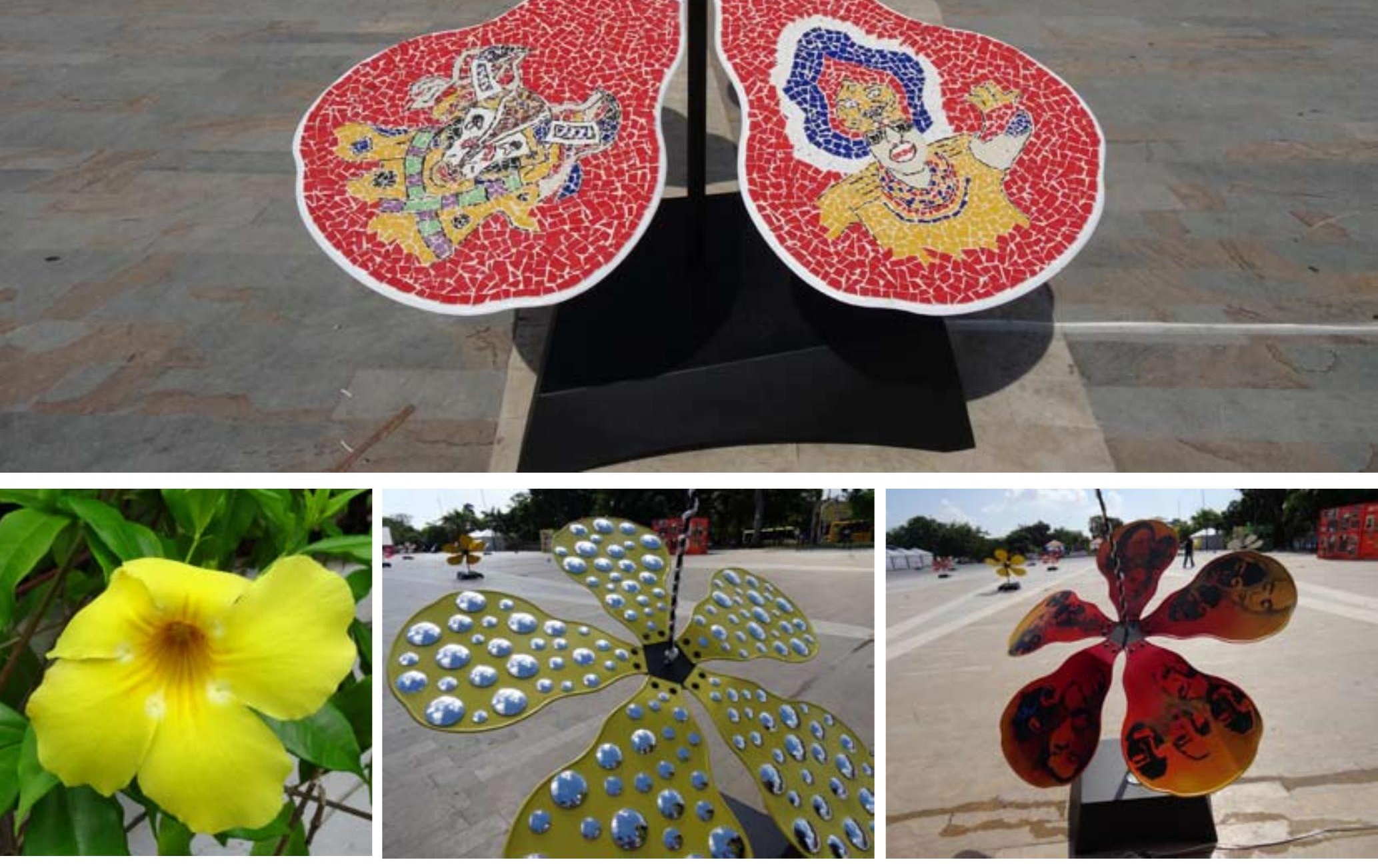

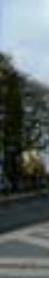
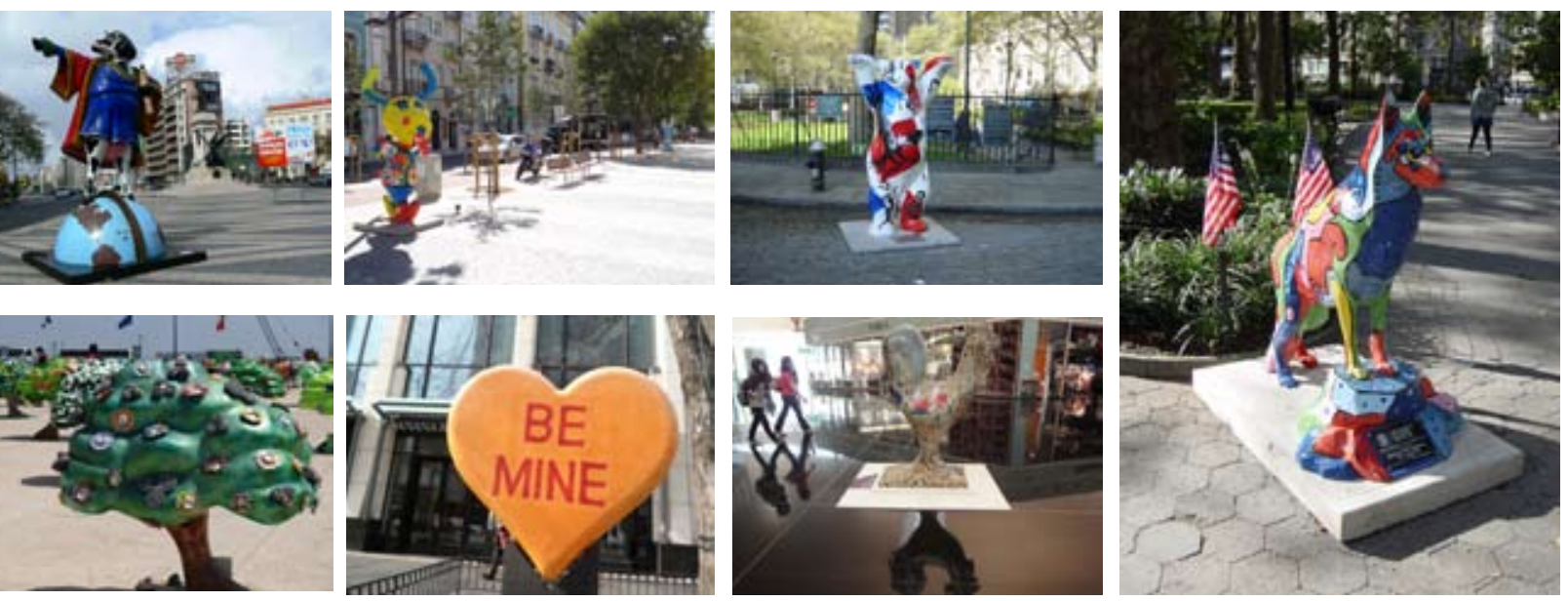

De izquierda a derecha: Cow Parade Lisboa 2006. Peanuts Parade Lisboa 2012. Buddy Bear New York 2002. Dogny New York 2002. Tree Parade Lisboa 2007. "Hearts a Bluhm" Chicago 2011. El qui porta la lluna Barcelona 2009 


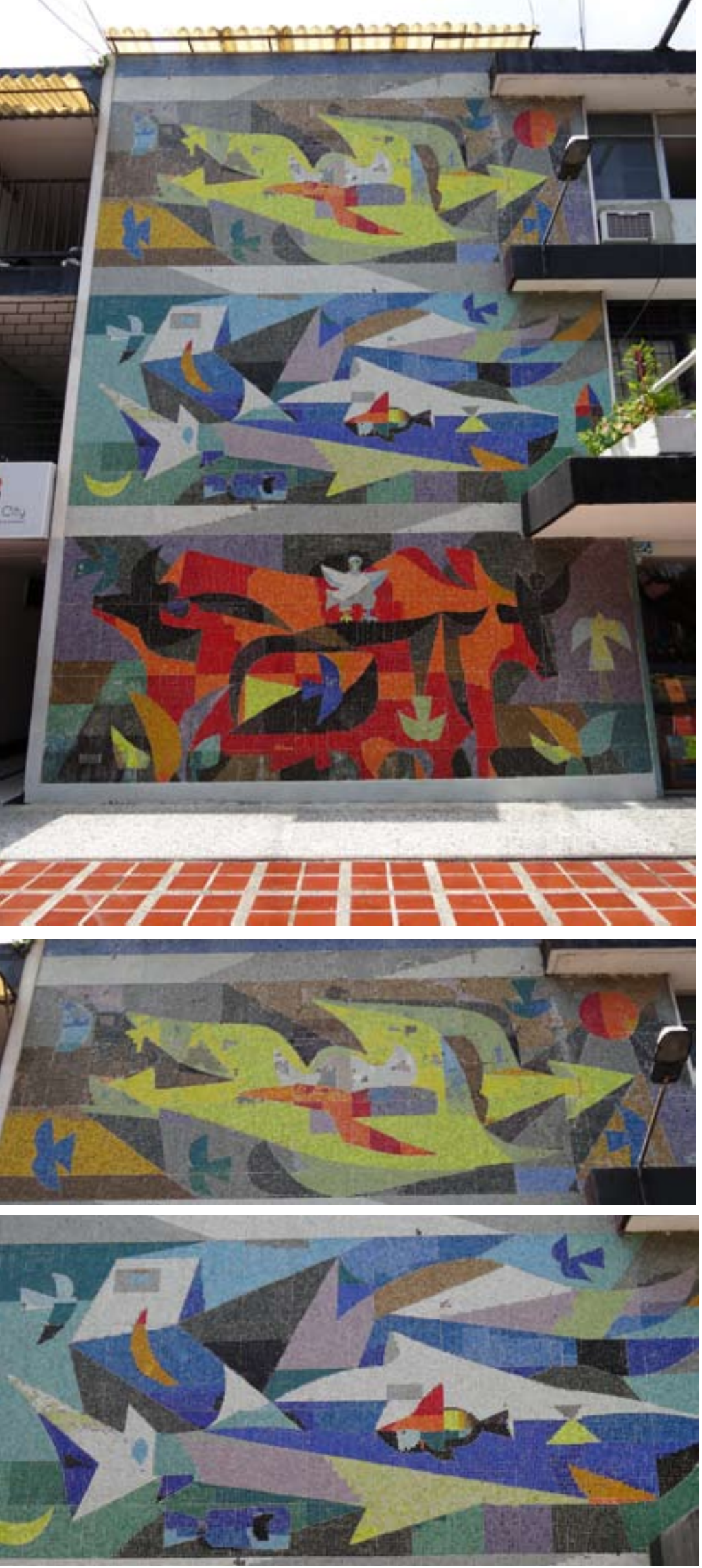

Al entrar en el barrio de El Prado - ¿cómo se puede saber el nombre de los barrios si se anda sin plano y sin conexión a Google maps?- , sobre todo si se accede a este barrio desde los barrios del norte de la ciudad no constatamos una diferencia esencial con otros lugares ya recorridos. En todo caso sorprende un edificio - el edificio Mezrahi, firmado por Ricardo González Ripoll, fundador de la Facultad de Arquitectura de la Universidad del Atlántico y alcalde de Barranquilla en dos ocasiones - con un mural cerámico fantástico. Firmado "Obregón 57".

Se trata de un tríptico mural de teselas, "Tierra, Agua, Aire" es su título. La obra se sitúa en el plano vertical del edificio y todo indica que tanto el arquitecto como el artista tuvieron contacto con Le Corbusier y J.L. Sert durante su estancia en Barranquilla en 1951. Por cierto, en aquel momento sert ya empezaba a hablar de la "integración de las artes" (Remesar, Antoni, 2016b; Sert, Josep Lluís, 2011).

Obregón fue un artista barcelonésbarranquillero exponente del "expresionismo mágico" que formó parte del "Grupo de La Cueva o de Barranquilla", junto a Gabriel García Márquez que dispone de su propio monumento en el Museo del Caribe. Muy cerca de este museo, dos obras más de obregón.

La primera en el Complejo Cultural de la Antigua Aduana. "Simbología de Barranquilla" es un fresco realizado en 1956 para el Banco 


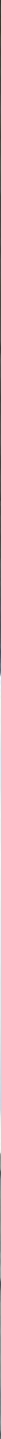




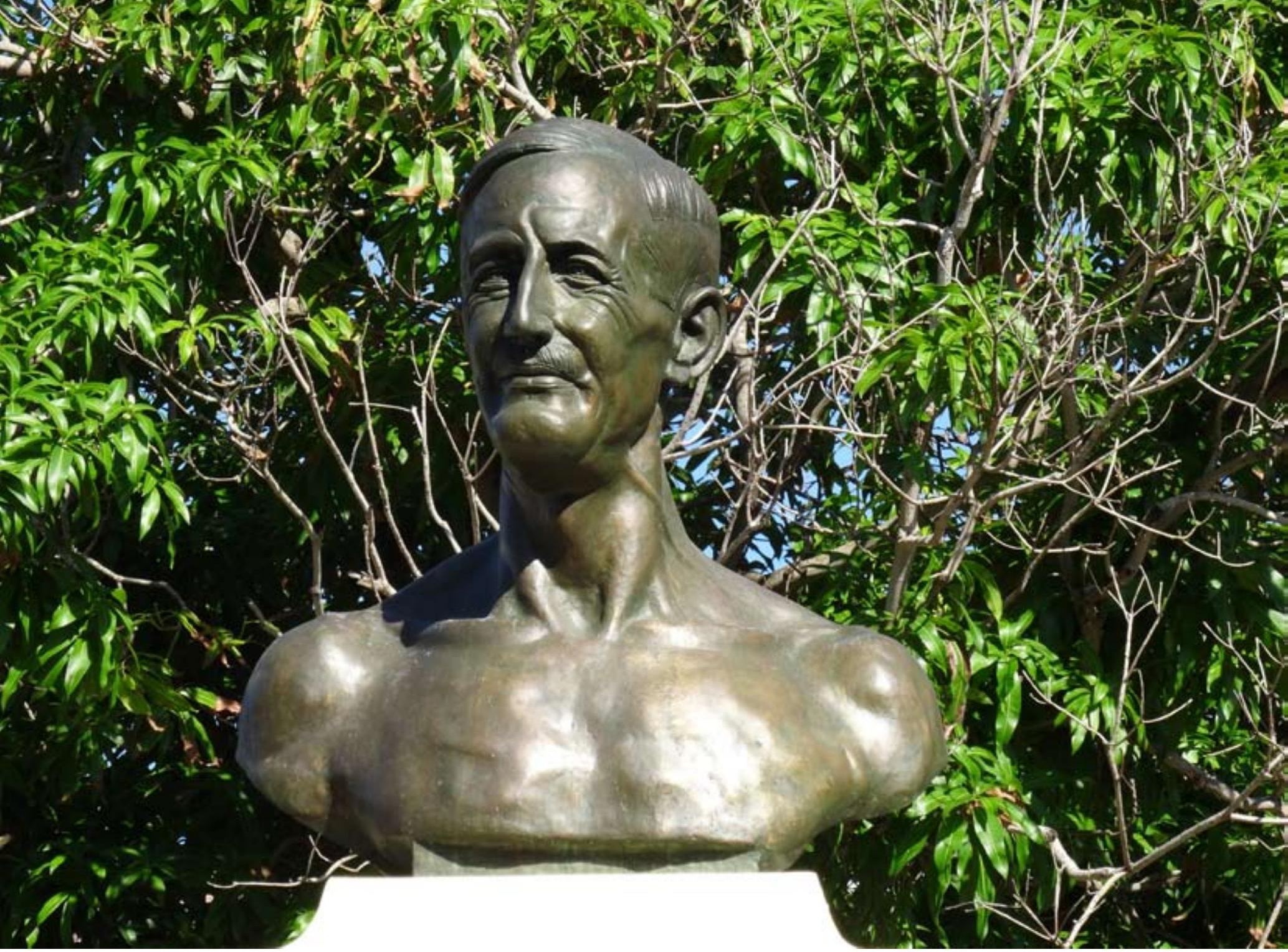

Monumento a Karl C. Parrish (bronce) de Michele Tepedino, 1945

Volvamos a El Prado. Al adentrarse en el barrio desde el parque Karl C.Parrish, se percibe un busto cuya placa nos dice que está dedicado a Karl C. Parrish. Un hombre de negocios norteamericano radicado en Barranquilla que fundó la compañía Urbanizadora de El Prado - entre otras muchas - y fue co-fundador de la Universiad del Norte (Posada,E 1986). El busto se inauguró en 1945 y es obra de Miguel Tepedino.

Percibimos algo particular en las edificaciones, una mezcla de construcciones modernas y en altura y una serie de villas o palacetes, todas ellas con antejardín. Muchos de estos palacetes están ahora ocupados por empresas, universidades o equipamientos culturales. Una suerte de sinfonía, algo cacofónica, de estilos "neo". Flashback.

El paisaje recuerda el paisaje de EI Vedado en La Habana. Amplias calles con aceras exuberantemente arboladas, los edificios antiguos con ante-jardín, los más actuales en línea de fachada. ¿ ¿Será una ciudad jardín?. 

otros autores prefieren hablar de barrios-jardín suburbanos(Bell Lemus, Carlos A., 2014).

Con la comparación (Barranquilla - Habana) en la cabeza se percibe que el trazado de ambos barrios difiere substancialmente. El Vedado posee una traza en damero basada en el cuadrado ${ }^{14}$. El Prado organiza la traza en rectángulo de dimensiones variadas. Incluso el recuerdo nos alerta que las edificaciones son bastante distintas en un barrio y en otro. No coinciden en morfología, ni en tipología edificatoria. Esto sí ambos comparten los jardines, los ante-jardines, la vegetación frondosa.

El proyecto de El Vedado arranca prácticamente al mismo tiempo que el
Proyecto de Reforma y Ensanche de Cerdà a mediados del siglo XIX. Por
cierto, si el plan de Cerdà se hubiera desarrollado según su propuesta
iestaríamos hablando ahora del Ensanche de Barcelona como ciudad jardín?

Afortunadamente por aquí estamos bastante más adelantados en esta materia que en Inglaterra como vamos a demostrar sin más que exponer en breves palabras el plan de la nueva ciudad, plan que ya examiné ó inventé y deseché por malo en mis artículos en El Progreso (1882).

La Ciudad-Jardín tiene de bueno el título que es bonito, sugestivo, simpático, pero nada más.

La planta geométrica de una Ciudad-Jardín se reduce á una plaza circular central y á unas cuantas calles circulares, anulares más bien, formando círculos concéntricos con el de la plaza y varias calles rectas que á modo de radios, parten de la plaza central en todas direcciones. A un anillo de casas, sigue otro de jardines, á este otro de casas, luego otro dé jardines y asi sucesivamente. A Jos diez ó doce anillos en que pueden albergarse 32.000 personas, máximun de población que se permite en una Ciudad-Jardín, se suspende la edificación, se pone "Completo", el resto del terreno, ó afueras de la población se dedica á trabajos agrícolas, huertas, bosques, y si la población aumenta se funda otra Ciudad-Jardín en otra parte.

Comparemos: La Ciudad Jardín es una ciudad punto, esto es, en la evolución progresiva de todas las formas de la naturaleza y del hombre, el grado inferior á la "Ciudad Lineal». Hay proporción entre estos cuatro términos: Mono es á hombre, como Ciudad-Jardín es a "Ciudad Lineal». En la Ciudad-Jardín las casas son de dos pisos y pegadas unas á otras en bloques ó grupos de seis ú ocho; en nuestra ciudad cada casa de uno, dos ó tres pisos, está completamente aislada de las demás con lo cual los problemas del incendio, del contagio, de la epidemia, de a ventilación, de los litigios frecuentes por las medianerías y otros se simplifican extraordinariamente.

iEn la Ciudad-Jardín las calles son de 32 metros! en la nuestra la calle principal tiene 40. Del suministro de aguas no hablan nada los fundadores de la Garden-city. Nosotros hemos empezado por satisfacer esta primera necesidad y creemos estar en lo cierto. En cuanto á las comunicaciones con el resto del planeta se contentan con que un punto cualquiera de la Ciudad-Jardín ó de sus afueras esté cerca de cualquier ferrocarril. De esto á convertir la vía férrea en médula espinal, en eje y base de sustentación de todo el organismo ciudad, como nosotros hacemos, hay la misma diferencia que en morfología comparada existe entre un invertebrado y un vertebrado.

Los demás problemas de la vida social que en número incalculable necesita resolver la vida moderna no pueden tener solución salpicando la superficie del planeta de ciudades puntos ó aglomeradas un poco mejores que las actuales por tener más jardines, más flores y más árboles.

La tienen perfectísima y completa convirtiendo cada vía de comunicación actual, ferrocarriles, carreteras y caminos vecinales, en ejes de las ciudades lineales futuras, en una inmensa triangulación cuyos vórtices sean las ciudades puntos actuales.

La génesis de la Ciudad-Jardín es ésta: un fabricante de chocolates hizo un pequeño pueblo para los obreros de su fábrica, bastante aceptable; otro fabricante de jabones construyó varias casitas para sus obreros en condiciones distintas, pero formando una pequeña ciudad, barriada ó conjunto de casas, algo mejor que lo que se acostumbra en casos parecidos.

Del cotejo de ambas barriadas obreras surgió en la mente de un señor Howard la idea de perfeccionarlas y se ha llegado á formar el plan que acabamos de exponer de la Ciudad-Jardín constituyendo para su realización una sociedad anónima con bastante más dinero que nosotros.

¿Qué lástima de dinero! En suma, la Ciudad-Jardín está en la lactancia: la "Ciudad Lineal», que también es CiudadJardín está á los diez años de su edad en una adolescencia sana y robusta y prometiendo á sus papas fundadores grandes esperanzas".(Soria, Arturo, 1904, pp. 5-6)

14.- Un trazado regular con manzanas de $100 \times 100 \mathrm{~m}$ 


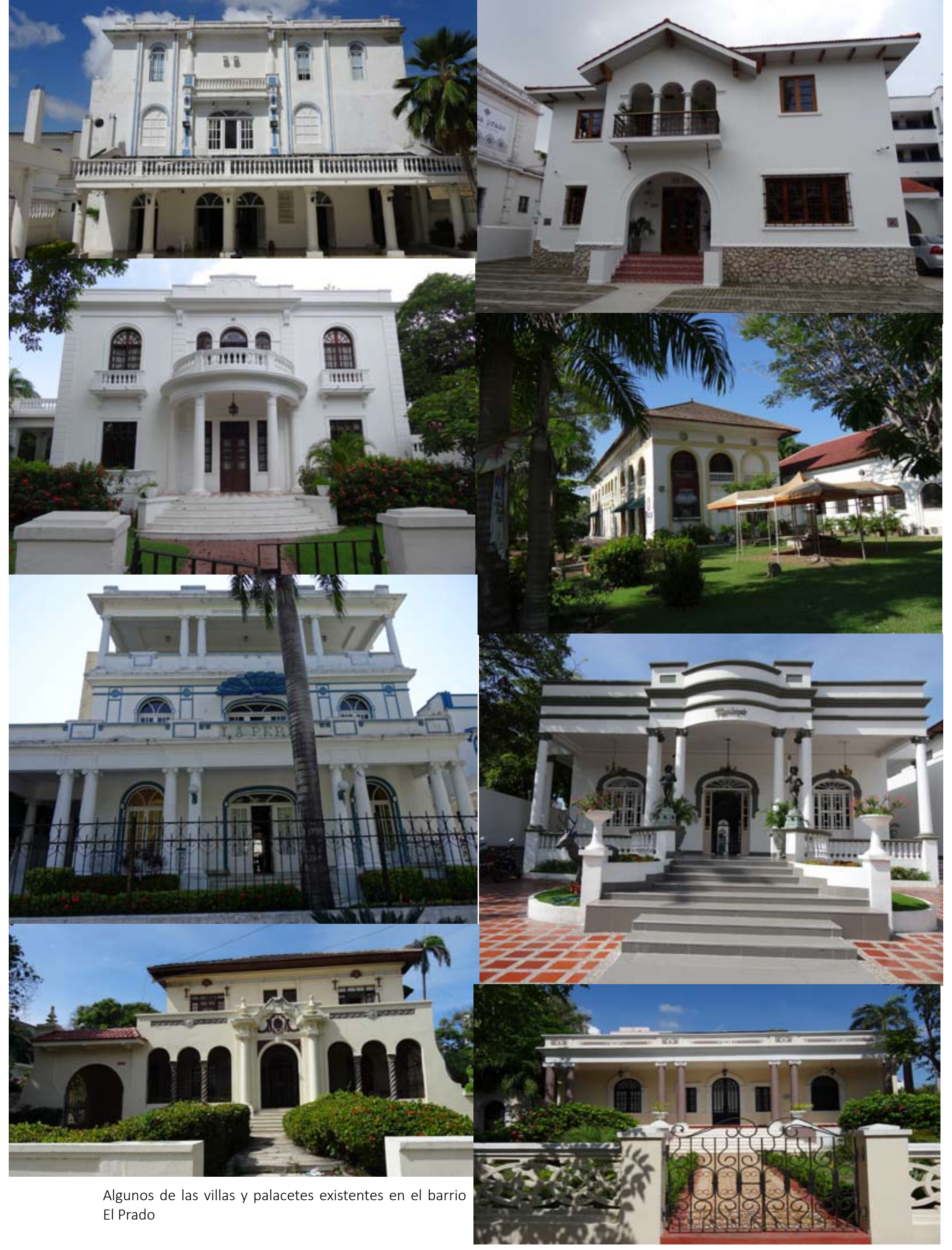


El Vedado surge en el contexto de la primera revolución industrial, y en el marco del pensamiento higienista y del problema de la vivienda en la definición de la ciudad industrial.

El Prado inicia su andadura en 1920, en el contexto de la segunda revolución industrial, en pleno auge del imperialismo, en el marco de los procesos de segregación espacial por raza o clase social, de la consolidación de lo que Veblen llamó clase ociosa (Veblen, Thorstein, 1899), una plutocracia urbana que por una parte se preocupaba por las mejoras urbanas- una oportunidad de negocio con las nuevas compañías constructoras de obra pública y de prestación de servicios urbanos, desde la electricidad al transporte público- y por otra se aislaba en barrios exclusivos

"The fact that suburbs were originally small and self-contained communities had still another effect on their development: it helped to re-create a new consciousness of something that had been lost in the rapid growth of the city-the sense of the neighbourhood" (Mumford, Lewis, 1961, p. 499)

Algunas investigaciones recientes (Eizaguirre, Xabier \& Crosas, Carles, 2006) apuntan que el Vedado de La Habana es un "'ensanche-jardín' producto del mestizaje entre la herencia hispánica y las influencias del suburbio anglosajón" (Crosas Armengol, Carles, 2009, p. 25). El Ensanche de Barcelona, si se hubiera mantenido íntegra la estructura diseñada por Cerdà15, entraría, también en esta categoría. El suburbio entendido como el conjunto de realizaciones en Inglaterra y los EE. UU ${ }^{16}$ previas a la formulación del concepto de ciudad-jardín por parte de Howard y que enlazan con el movimiento "back to the nature" propugnado por Olmsted. como señala ch. Boyer
"This "back to nature" movement, which spread across the urban mentality of the late nineteenth century, valued woodland and meadows for their spiritual impact; they were places of simple virtues and pleasures on the edge of urban disquietudes and troubles" (Boyer, M. CH, 1983)

15.- Recordemos que Cerdà reclamaba que el interior de las manzanas deberían tener un "square" que serian "un instrumento de salubridad general de toda la población, porque vienen a enrarecer el número de individuos que viven sobre una superficie dada, y viene hasta cierto punto a rurizar las ciudades, armonizando en ellas la vida del espíritu con la vida física que en tan íntima relación deben hallarse"(Cerdà, Ildefons, 1859, p. ep. 1495)

16.- "The first American picturesque suburb is probably Glendale, Ohio, founded in 1851. The designer was Robert C. Phillips.(....) At Riverside, Illinois, in 1869, Olmsted took a piece of flat prairie land and changed it into a romantic landscape. Thousands of trees were imported. A fluent system of curved streets was inscribed. Curved streets "suggest and imply leisure, contemplativeness, and happy tranquillity," Olmsted wrote, in contrast to straight streets which implied "eagerness to press forward, without looking to the right or left." Riverside was called "a suburban village," and openly touted as being for "the more intelligent and more fortunate classes." Indeed, the Olmstedian residential development, always exceptional within the overwhelming rectilinearity of suburban tracts, became the province of well-off white Anglo-Saxon Protestants, to the covenanted exclusion of all other types of Americans-Blacks, Jews, Italians, and other ethnic groups that joined the melting pot in the course of time".(Kostof, Spiro, 1991, pp. 74-75) 

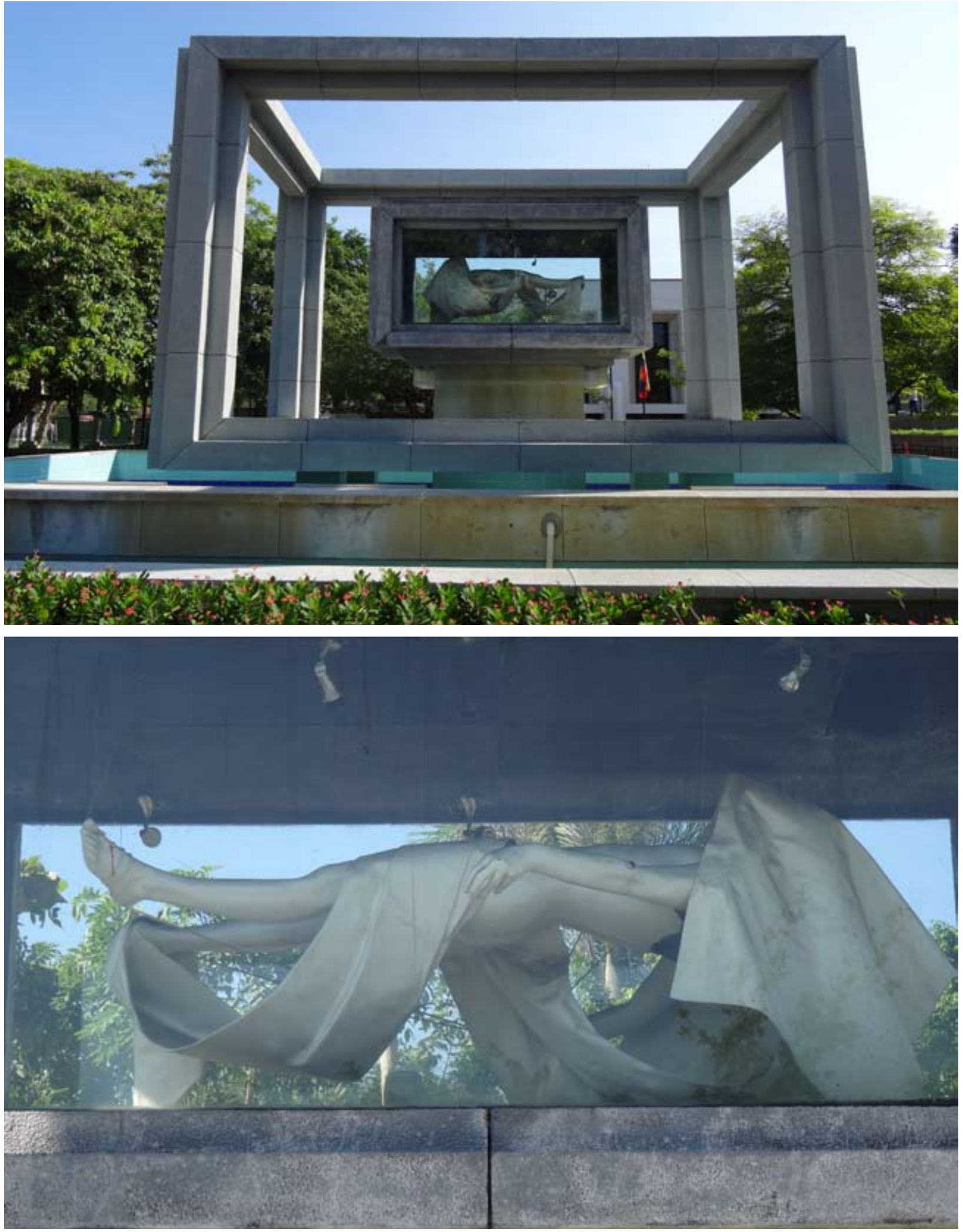

"Io peor del parque es el tal 'Héroe Caído', una estructura que ha sido denominada por algunos, con toda razón, "la momia". Se trata de un monumento a la muerte, tétrico, fúnebre y oscuro, que más despierta espanto que admiración. El conjunto es sencillamente grotesco y mal elaborado, el súmmum del mal gusto. En una ciudad que irradia tanta alegría como Barranquilla, que es esencialmente pletórica de luz, reconocida como tal por propios y extraños, un monumento a la muerte es el colmo del contrasentido. Francamente, Barranquilla no merece una equivocación tal. Es una verdadera lástima que mi Universidad del Norte, en cabeza de su culto rector, haya hecho parte de la realización de una obra que de todo tiene, menos de artística". (La cuestión barranquillera, 2007) 


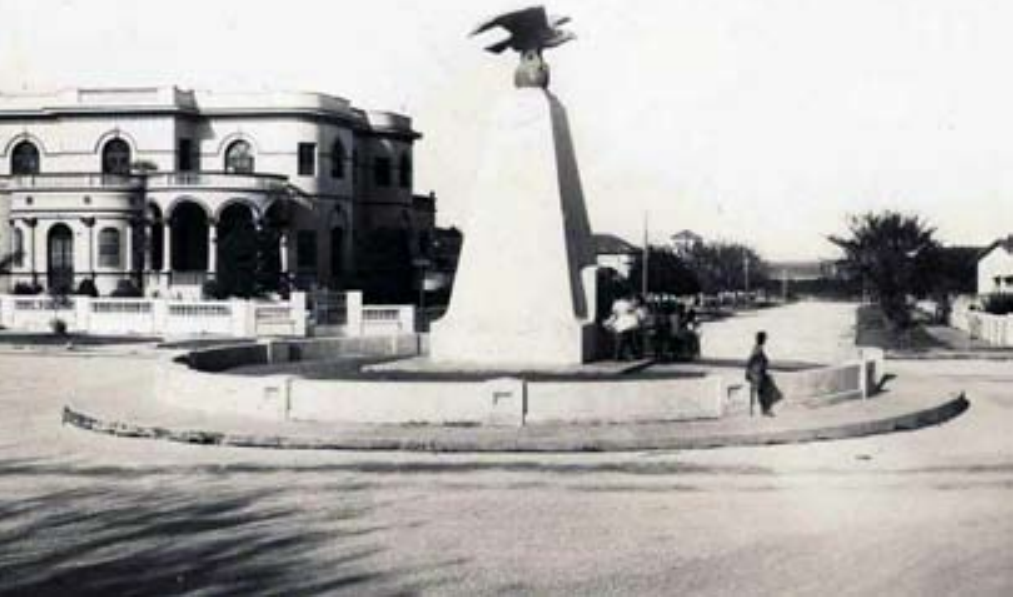

Monumento a las primeras víctimas de la aviación. c.1926 Fuente: Archivo Karl C.Parrish. Universidad de Norte

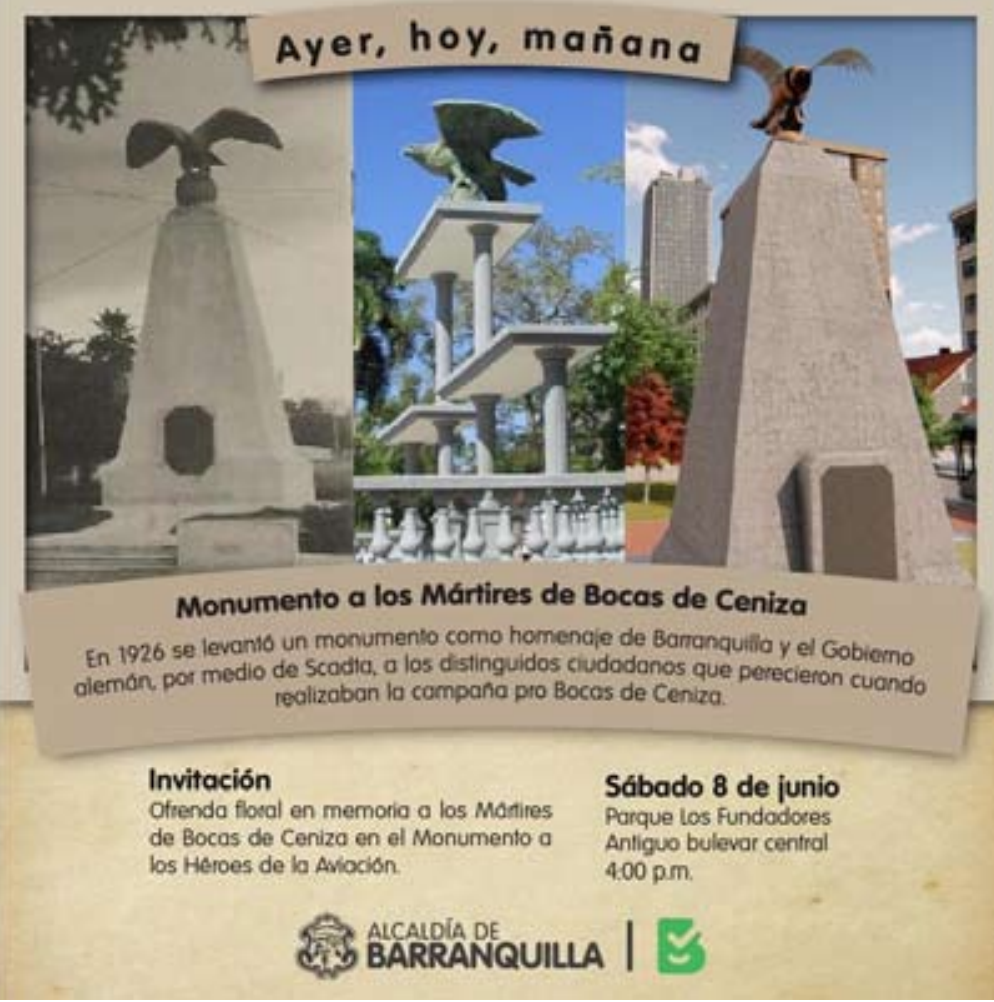

Invitación acto inauguración re-construcción Monumento a las primeras víctimas de la aviación. 2019. Fuente: Alcaldía de Barranquilla

El actual Parque de los Fundadores, fue diseñado como el Boulevard Central de la Urbanización El Prado en la segunda década del siglo $\mathrm{XX}$, no se entiende que se plantee la idea de que este trecho de la urbanización de unos 250m. lineales pueda considerarse "ciudad lineal"?. La de Madrid, la de Arturo Soria, es 10 veces más larga. Al final del boulevard se abría una rotonda en la que, inicialmente, se colocó el monumento a los "fundadores". Esta vez el águila encaramada a un pedestal. Esta configuración ha sido restaurada recientemente (2019).

En el extremo final, en lo que otrora fuera llamado Prado Viejo, y el límite de El Prado, se abre el parque 11 de Noviembre. Allí, en la esquina, se alza un monumento blanco, alto, esbelto. En su cima una mujer con gorro frigio portando una bandera al viento. En la parte superior del pedestal el escudo de Colombia. En la base un tríptico con tres piezas. A la izquierda, sobre un fondo de vegetal, tres figuras. Por los rasgos faciales, el collar que luce y su semi desnudez, parece identificarla con una indígena. Las otras dos figuras parecen una madre que cobija a su hijo portador de una espada y de una corona de hojas de roble. En el centro, parece un altar, con un aparente libro rodeado de laureles, ¿podría ser la Constitución? A la derecha, tres figuras, una femenina y dos masculinas, portando los símbolos de las artes. Un monumento republicano de mármol que bien podría ser de Carrara. Su emplazamiento es curioso, da la espalda a la calle, se orienta hacia el interior del parque. Es un análisis visual puesto que el monumento no dispone de ninguna placa.

Es el monumento a la Bandera obra del escultor Marco Tobón Mejía realizado en 1931 y tiene 15 metros de altura. La placa de bronce que daba cuenta de toda la información pertinente para los ciudadanos fue robada unos años atrás. 
Monumento a la Bandera (marmol)

obra de Marco Tobón. 1931
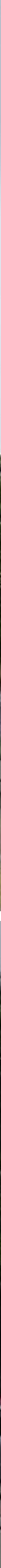
Cristo Libertador Latinoamericano (bronce) obra de Rodrigo Arenas Betancourt 1986 
Este ejercicio de estilo, indica que abordar el estudio del arte público de un determinado territorio, requiere conjugar de saber adquirido mediante la acción corporal -sensaciones y percepciones que contextualizan- con el saber adquirido por la acción reflexiva (estudio, investigación documental, etc.).

Estas acciones - tanto la corporal como la mental-son poliédricas, es decir que requieren procesar información proveniente de distintos ámbitos de lo sensorial y del conocimiento. Requiere, también, organizar el pensamiento de modo que permita relacionar lo diverso desde lo concreto a lo abstracto y viceversa. Para ello la metodología de aproximación debe estar clara, mediante unas reglas, que enmarquen el proceder.

Una primera es anteponer el dato perceptivo y su descripción a la categorización, infiriendo marcos conceptuales de modo inductivo. En este sentido, es bueno organizar los datos recopilados observacionalmente, a modo de Atlas, en la dirección que ya hace tiempo señalaran Warburg (Warburg 1927-1929) o Malraux (Malraux, 1965) pero organizándolos mediante categorias espaciales urbanas y no mediante las categorías "estilísticas" provenientes de la historiografía del Arte. En este sentido, no importa el "valor" historiográfico de las obras.

Las obras de arte público que se ubican en el espacio público, forman parte de los procesos de diseño urbano. Estas obras, como han señalado algunos autores (Bohigas, Oriol, 1985; Lecea, Ignasi de, 2004) las podemos considerar "monumentos", y como señala Vattimo los monumentos constituyen la sustancialidad de la transmisión histórica (Remesar, Antoni, 2016a) . Responden, en primer lugar a una época, en segundo lugar a un contexto urbano y espacial. En este sentido, no importa el "valor" historiográfico de las obras.

Una segunda regla, lo que importa es el "valor" que la obra pueda tener en el entorno urbano. Por ello, siguiendo a Debray (Debray, Régis, 1989) no importa tanto la contemplación y posterior análisis del "monumento como forma" sino su percepción y análisis de "forma como monumento"-un percepto-concepto abstracto-, es decir como 


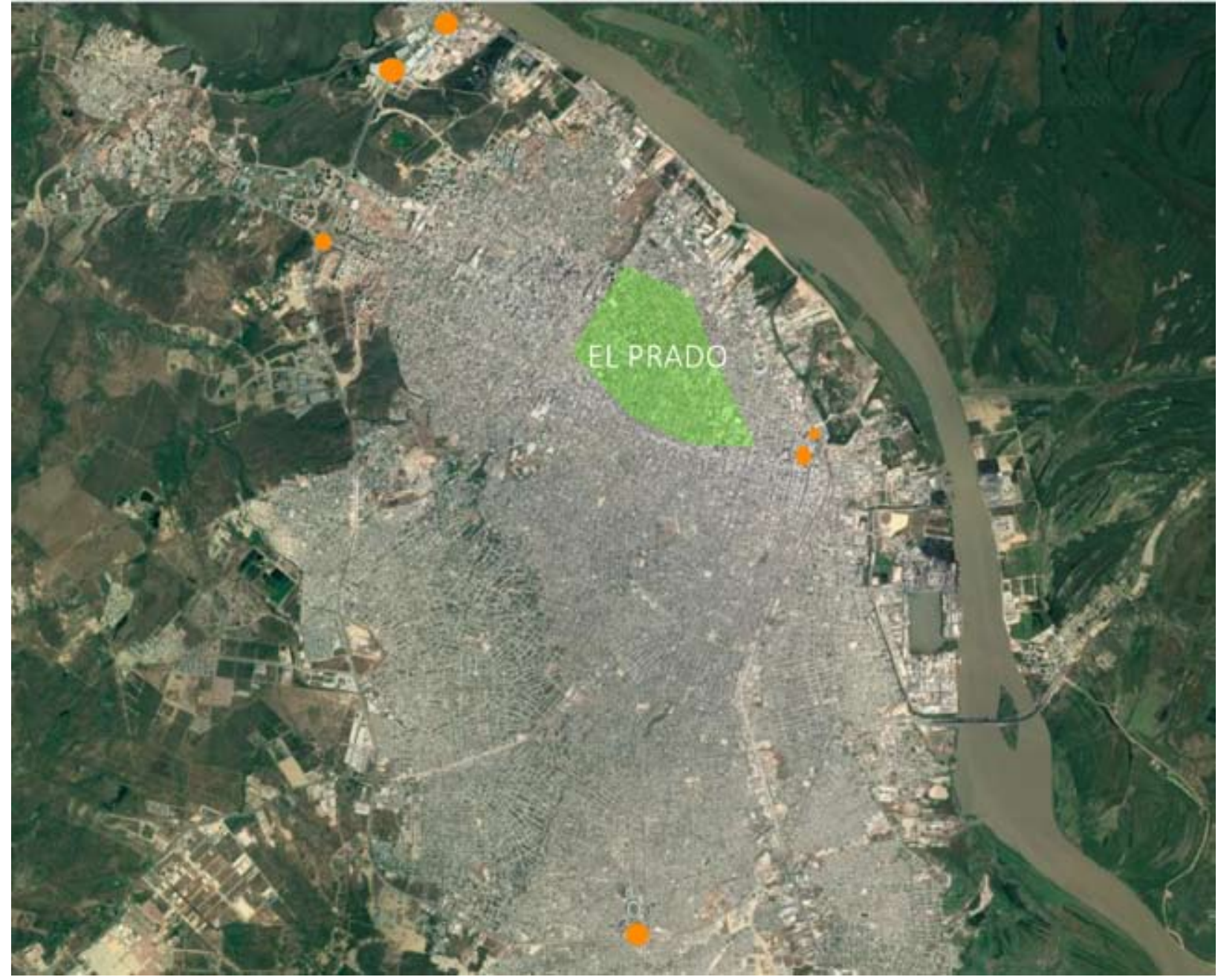

Monumentos situados en el anillo periférico de la ciudad. Imagen base Google Earth

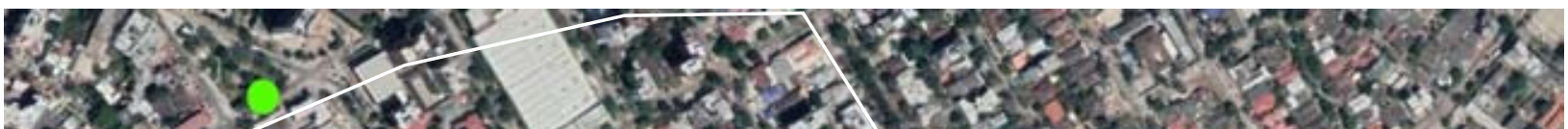

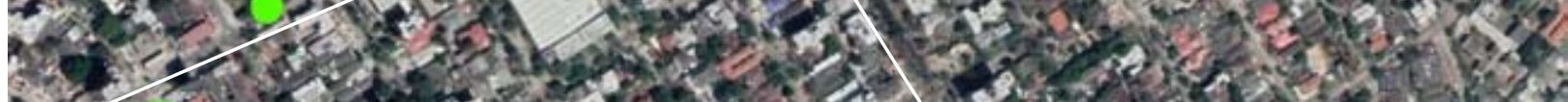

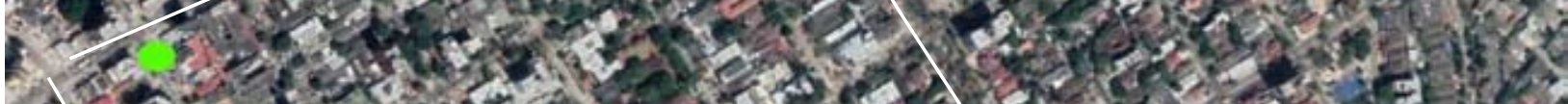

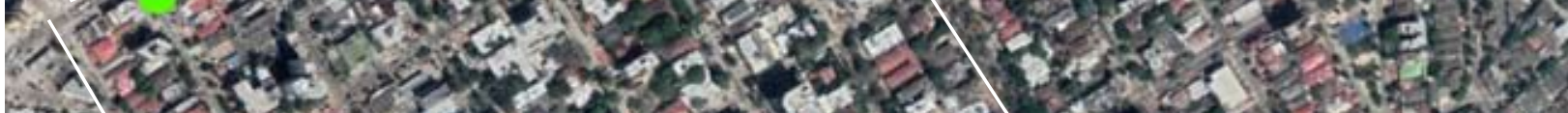

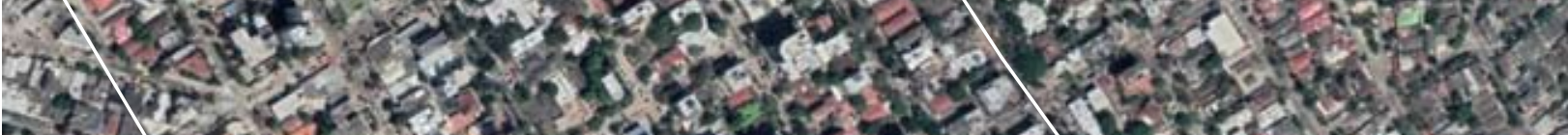
7. 20 a

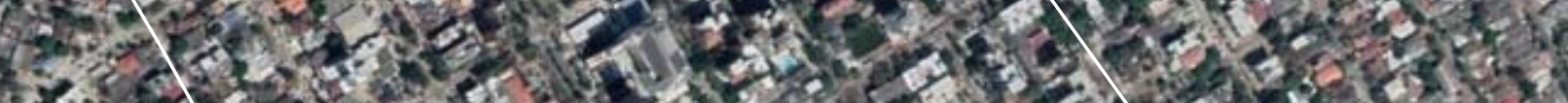

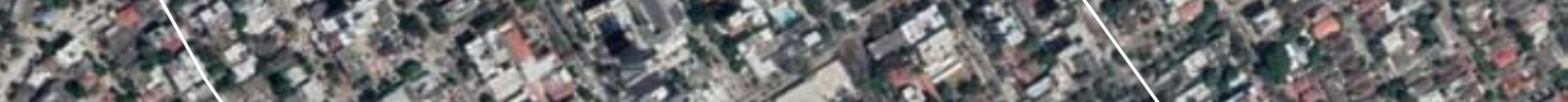

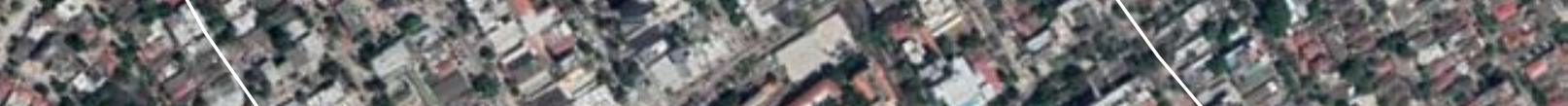

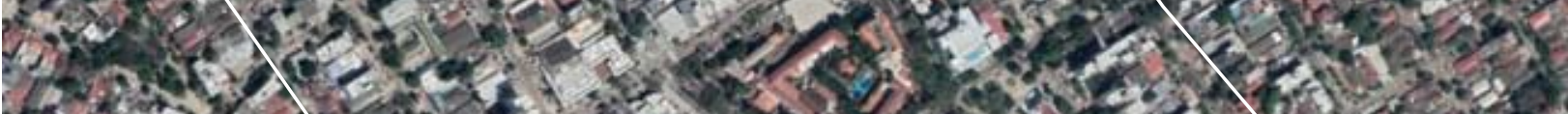
- 1251 .

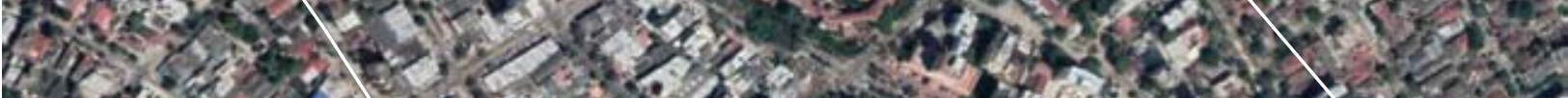

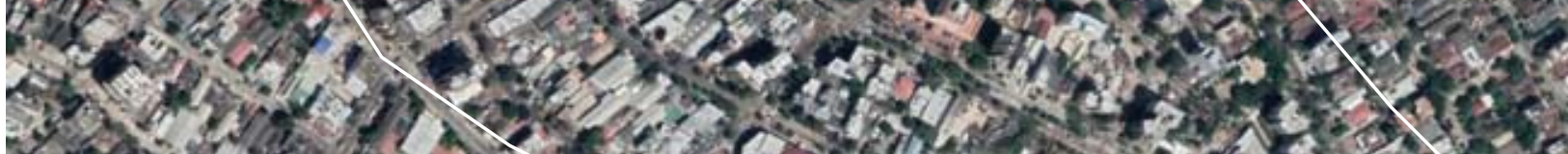

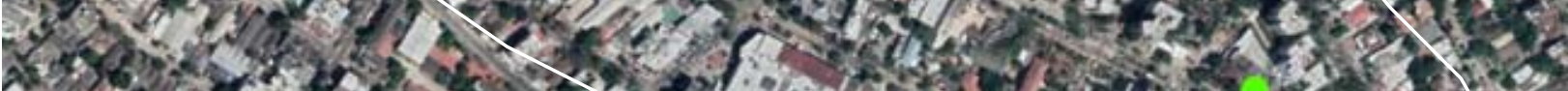

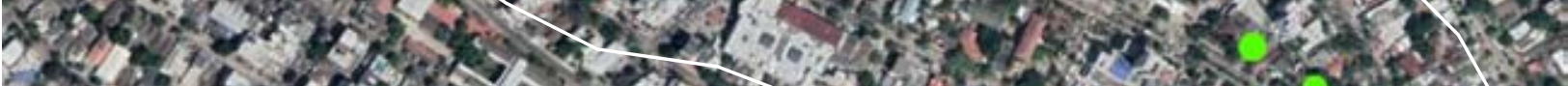

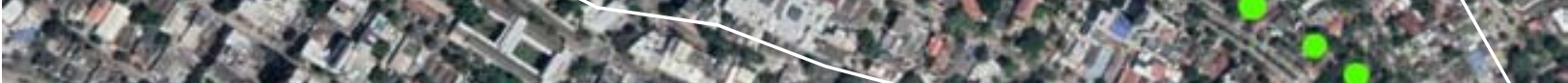

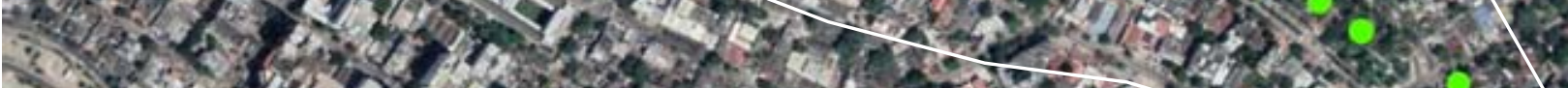

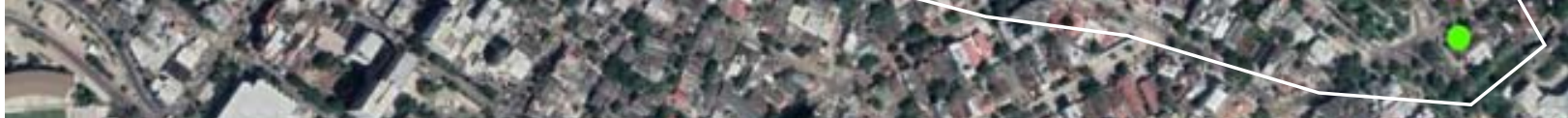

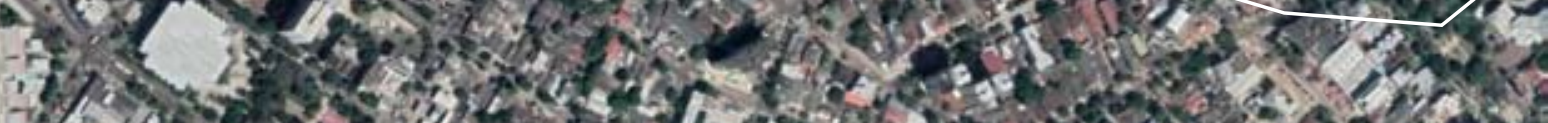

Los monumentos de El Prado. Están situados en las entradas del barrio. Imagen base Google Earth 
un artefacto más de los que coadyuban a la creación del paisaje urbano, a la organización del decorum urbano y distinguible del resto de los artefactos por destacar diferencialmente en su entorno, por no poderle atribuir utilidad o por reconocerlo como elemento con una cierta carga simbólica.

En este sentido el monumento se define por situarse, por lo general, en un espacio "negativo" (no es un edificio, no es un árbol, no es mobiliario urbano). Entendido así, el monumento "contribuye a constituir el fondo de nuestra experiencia aunque por sí misma la obra por lo general es objeto de una percepción distraída" (Vattimo, Gianni, 1986, p. 80).

Ciertamente, para conseguir entender el "valor" de la obra es preciso desenvolver una serie de operaciones conceptuales que articulamos con la línea del tiempo. Estudiar el "cuando" acontece es importante, no sólo para la datación historiográfica de una pieza, sino para su comprensión desde el punto de vista de la lógicas urbanas. Debemos reconocer que el artículo no ha profundizado - tampoco era su intención aunque según los datos disponibles presenta aproximadamente el 36\% de las esculturas y obras de arte público de la ciudad- en las lógicas urbanas de Barranquilla, menos en el aspecto de las políticas urbanas.

El artículo tampoc ha explorado en profundidad el conjunto del arte público de la ciudad. Es únicamente una primera aproximación. El estudio del arte público de una ciudad requiere de tiempo, de mucho andar y de mucho investigar las dimensiones antes señaladas. Por ejemplo, la constatación de que un único escultor ha realizado el 14\% de las esculturas de la ciudad entre 2000 y 2020, nos llevaría a investigar los procedimientos de los encargos. Unos encargos que, además, constatamos están penetrados por la lógicas propias de otras instituciones, como puede ser la Universidad, y que se fundamentan en el parocinio de la empresa privada. Tampoco es muy comprensible tanto el monumento a Shakira como el busto inaugurado en 2018 dedicado al alcalde Alejandro Char que ostentaba, en aquel momento, su segundo mandato como Alacalde. No sabemos nada a ciencia cierta sobre la política de artepúblico de esta ciudad caribeña .

Podemos concluir que la "carga monumental" del arte público de El Prado es relativamente pobre en relación a otras obras situadas en 
la periferia de la ciudad - aunque se aprecian "vacios" enormes en la colocación de obras de arte público. Prácticamente no existe ninguna obra que ayude a articular -significándolo- el espacio público, puesto que se concentran en un espacio "contenedor" -parques- donde adquieren una condición de ornamento -una de las condiciones posibles del arte público-al confundirse las formas con el paisaje, perdiendo su condición de figura sobre un fondo. Parques y sitios a la entrada el antiguo recinto del barrio El Pardo ¿continúa la idea elitista de un espacio segregado?

Aunque el artículo ha demostrado que la caracterización urbana de El Prado, no deriva, propiamente, de los postulados del movimiento de la ciudad-jardín, sino de los planteamientos del "suburbio jardín" desarrollados en el mundo anglo-sajón con anterioridad al movimiento general de las ciudades-jardín, sorprende la escasez de "monumentos" de arte público, máxime cuando los barrios El Prado, Altos del Prado y Bellavista, están declarados Bienes de Interés Cultural de ámbito nacional por sus valores históricos, arquitectónicos y urbanísticos. Una decisión protectora que anteriormente adoptó la Junta del Area Metropolitana de Barranquilla por la que esos mismos barrios se consideraban áreas de conservación urbanística y arquitectónica.

\section{REFERENCIAS}

ALCALdíA De BARRANQUilla. (2012). Plan de Ordenamiento Territorial. Documento Técnico de Soporte-Libro I: Componente General. Alcaldía de Barranquilla

BELL LEMUS, CARLOS A. (2014). Barranquilla, modernización y movimiento moderno (1842 -1964) [Doctoral, Universidad Nacional de Colombia-Sede Bogotá]. http://bdigital.unal.edu.co/65767/

BOHIGAS, ORIOL. (1985). Reconstrucció de Barcelona. Edicions 62.

BOYER, M. CH. (1983). Dreaming the Rational City. The Myth of American City Planning,. The MIT Press.

CERDÀ, ILDEFONS. (1859). 'Teoría de la Construcción de las ciudades aplicada al proyecto de Reforma y Ensanche de Barcelona'. En In Busquets, Joan (Coord). Teoría de la construcción de las ciudades. Cerdà/ Barcelona. (1991. a ed., Vol. 1). MAP- Ajuntament de Barcelona.

CROSAS ARMENGOL, CARLES. (2009). Variaciones sobre la regularidad: El proyecto de el Vedado en la formación de la Habana metropolitana [Doctoral, Universitat Politècnica de Catalunya]. http://hdl.handle.net/10803/78009

DEBRAY, RÉGIS. (1989). 'Trace, forme ou message?' Cahiers de la Mediológie, N7 La confusion des monuments, 27-44. http:// www.mediologie.org/cahiers-de-mediologie/07_monuments/sommaire07.html

EIZAGUIRRE, XABIER, \& CROSAS, CARLES. (2006). El Vedado. La Habana. Proyecto y Transformación. Edicions ETSAB. https:// upcommons.upc.edu/bitstream/handle/2117/7345/13\%20-\%20El\%20Vedado.pdf

GARCÍA FARIA, PEDRO. (1891). Proyecto de Saneamiento del subsuelo de Barcelona: Alcantarillado-Drenaje-Residuos urbanos (C02.02 C02.02 Subcol-lecció de plànols urbans generals; 1893. ${ }^{a}$ ed.). Imprenta de Henrich y Compañía, Sucesores de N. Ramírez y Compañía; Arxiu Històric de la Ciutat de Barcelona (AHCB). 
HALL, PETER. (2014). Cities of Tomorrow. An Intellectual History of Urban Planning and Design Since 1880 (1988) (4rth Edition). Blackwell Publishing Ltd.

HOWARD, EBENEZER. (1898). To-morrow: A Peaceful Path to Real Reform. S. Sonnenschein \& Co., Ltd. http://www.sacred-texts. com/utopia/gcot/index.htm

HOWARD, EBENEZER. (1902). Garden Cities of Tomorrow. S. Sonnenschein \& Co., Ltd. http://www.sacred-texts.com/utopia/gcot/ index.htm

KOSTOF, SPIRO. (1991). The City Shapped. Urban Patterns and Meannig trough History (Revisions by Greg Castillo). Thames \& Hudson.

KROPOTKIN, P. (1898). Fields, Factories and Workshops: Or Industry Combined with Agriculture and Brain Work with Manual Work (2a ed. 1912). Thomas Nelson \& Sons.

LECEA, IGNASI DE (2004). 'Arte Público, Ciudad y Memoria'. On the w@terfront [en línia], 5, 5-17. https://raco.cat/index.php/ Waterfront/article/view/214755/285047

MALRAUX, ANDRÉ. (1965). O Museu Imaginário (2000.a ed.). Ediçoes 70.

MUMFORD, LEWIS. (1961). The city in History. Its Origins, its tranformations and its propscects. Harcourt Brace Jovanovich, Inc. POSADA CARBÓ, EDUARDO. (1986). 'Karl C. Parrish, un empresario colombiano en los años 20.' Boletín Cultural y Bibliográfico, 23(8), 3-20. https://dialnet.unirioja.es/servlet/articulo?codigo=5460068

REMESAR, ANTONI. (2016a). '¿Monuments vs Memorials? Some doubts, some reflections, No proposals?' En Ricart, N (ED) Public Space and Remembrance. Publicacions i Edicions de la Universitat de Barcelona.

REMESAR, ANTONI. (2016b). 3New Urban Decorum? Aesthetics To and Fro3. En In Gralińska-Toborek;A-Kazimierska-Jerzyk, W (ED) Aesthetic Energy of the City (pp. 19-54). Wydawnictwo Uniwersytetu Łódzkiego (Łódź University Press). https:// wydawnictwo.uni.lodz.pl/produkt/aesthetic-energy-of-the-city/

REMESAR, ANTONI. (2017). 3Decoro Urbano. Apuntes de ida y vuelta sobre Arte, Espacio Público y Ambientes de calidad3. Módulo Arquitectura CUC, 19, 9-20. https://doi.org/10.17981/moducuc.19.1.2017.01

SERT, JOSEP LLUÍS. (2011). 'The relationship of painting and sculpture with Architecture' (1951). En In Patricia Juncosa (ED) Josep Llúis Sert. Conversaciones, esritos. Lugares de encuentro para las artes. Gustavo Gili.

SORIA, ARTURO. (1904). 'Garden-City. La Cité Jardin'. La Ciudad Lineal, 211, 5-6.

TOBÓN, ANÍBAL, \& VASQUEZ, SANDRA. (2013). Los monumentos hablan en Barranquilla. Universidad del Norte.

VATTIMO, GIANNI. (1986). 'Ornamento y Monumento'. En El fin de la Modernidad. Nihilismo y Hermenéutica en la cultura posmoderna (p. 159). GEDISA.

VEBLEN, THORSTEIN. (1899). The Theory of the Leisure Class An Economic Study of Institutions (Castellana. Fondo de Cultura Económica. México, 1944). Macmillan Co.

VILLALOBOS. JOSÉ DAVID (2007, marzo 22). Esperpento en el parque de los Fundadores [Website]. La cuestión barranquillera. https://sites.google.com/site/jdvillalobos/adefesios

WARBURG, ABY. (1927, 1929). Online BilderAtlas Mnemosyne [Website]. The Warburg Institute. https://warburg.sas.ac.uk/librarycollections/warburg-institute-archive/online-bilderatlas-mnemosyne

NOTA: Las imágenes en la que no consta una fuente específica provienen del archivo del CR POLIS. Universitat de Barcelona 